\title{
Corrigendum
}

\section{Corrigendum to "Development of a Tool to Identify Poverty in a Family Practice Setting: A Pilot Study"}

\author{
Vanessa Brcic, Caroline Eberdt, and Janusz Kaczorowski \\ Department of Family Practice, Faculty of Medicine, University of British Columbia, 3rd floor David Strangway Building, \\ 5950 University Boulevard, Vancouver, BC, Canada V6T 1Z3
}

Correspondence should be addressed to Vanessa Brcic; vanessabrcic@gmail.com

Received 17 August 2015; Accepted 7 September 2015

Copyright (C) 2015 Vanessa Brcic et al. This is an open access article distributed under the Creative Commons Attribution License, which permits unrestricted use, distribution, and reproduction in any medium, provided the original work is properly cited.

In the paper "Development of a Tool to Identify Poverty in a Family Practice Setting: A Pilot Study" [1], two different specificity values were provided in the paper for the study question "Do you [ever] have difficulty making ends meet at the end of the month?" The correct values for this question are a sensitivity $98 \%$; specificity $40 \%$; OR $32.3,95 \%$ CI $5.4-$ 191.5. The specificity was incorrectly reported as $60 \%$ in the abstract and in page 2 .

\section{References}

[1] V. Brcic, C. Eberdt, and J. Kaczorowski, "Development of a tool to identify poverty in a family practice setting: a pilot study," International Journal of Family Medicine, vol. 2011, Article ID 812182, 7 pages, 2011. 


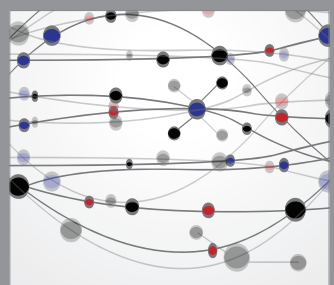

The Scientific World Journal
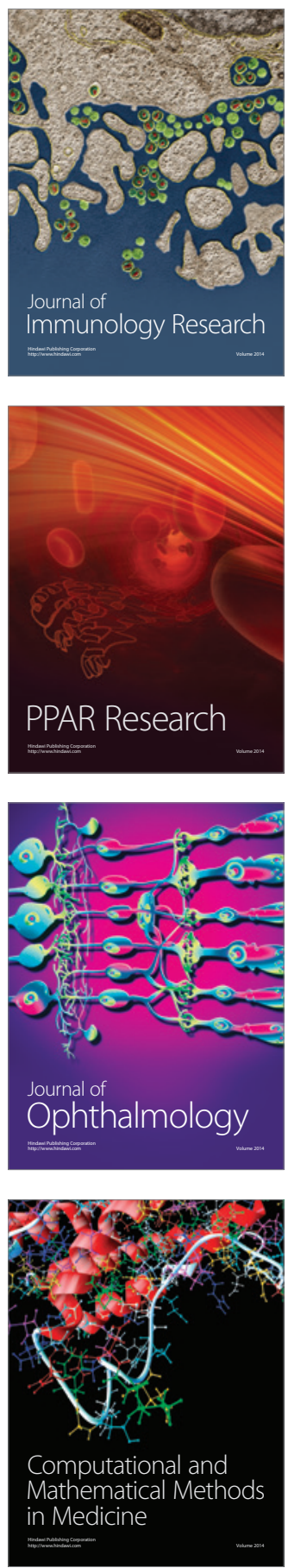

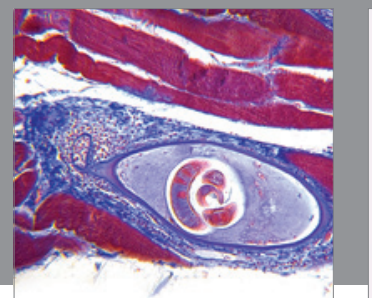

Gastroenterology

Research and Practice
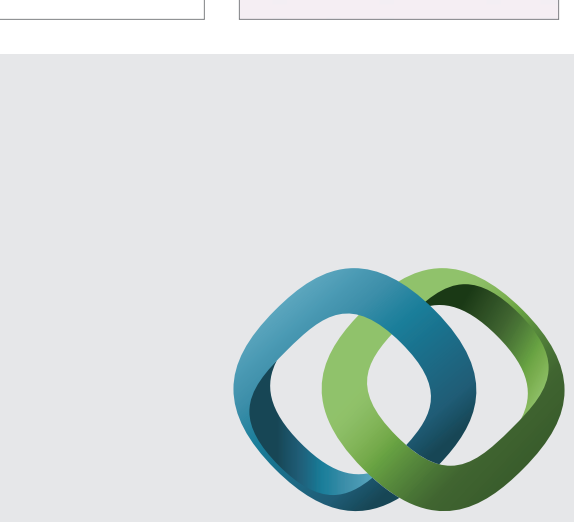

\section{Hindawi}

Submit your manuscripts at

http://www.hindawi.com
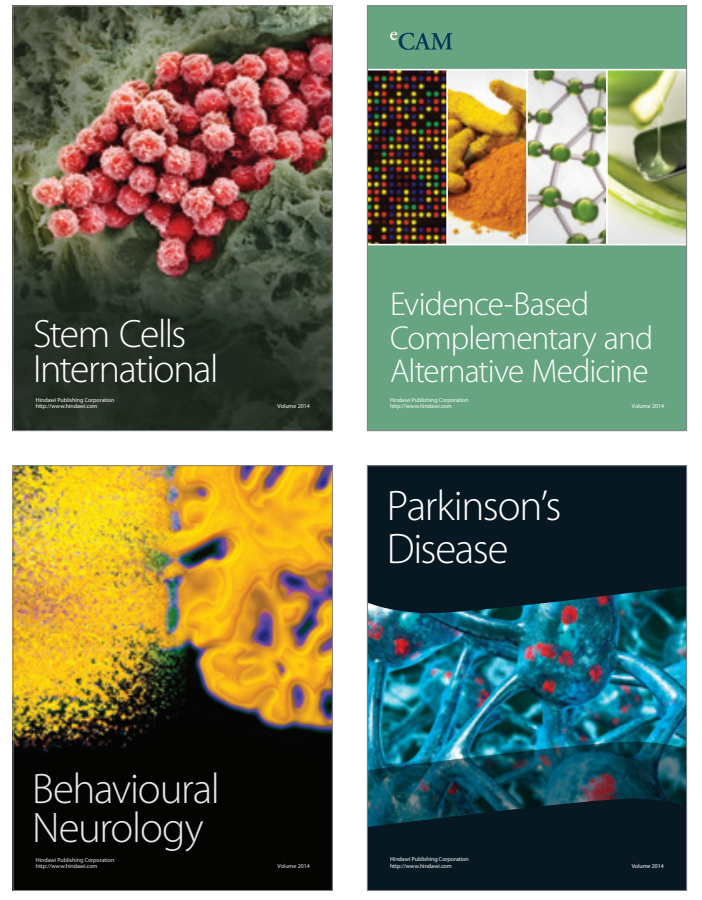
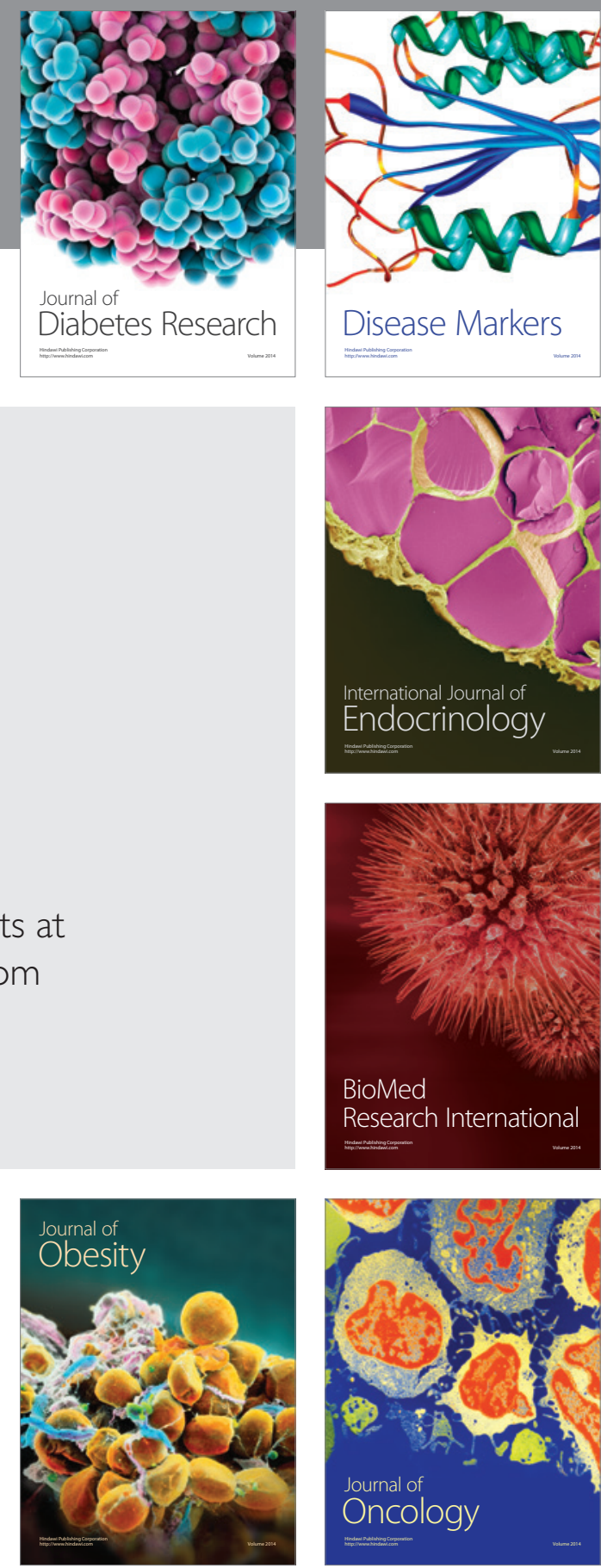

Disease Markers
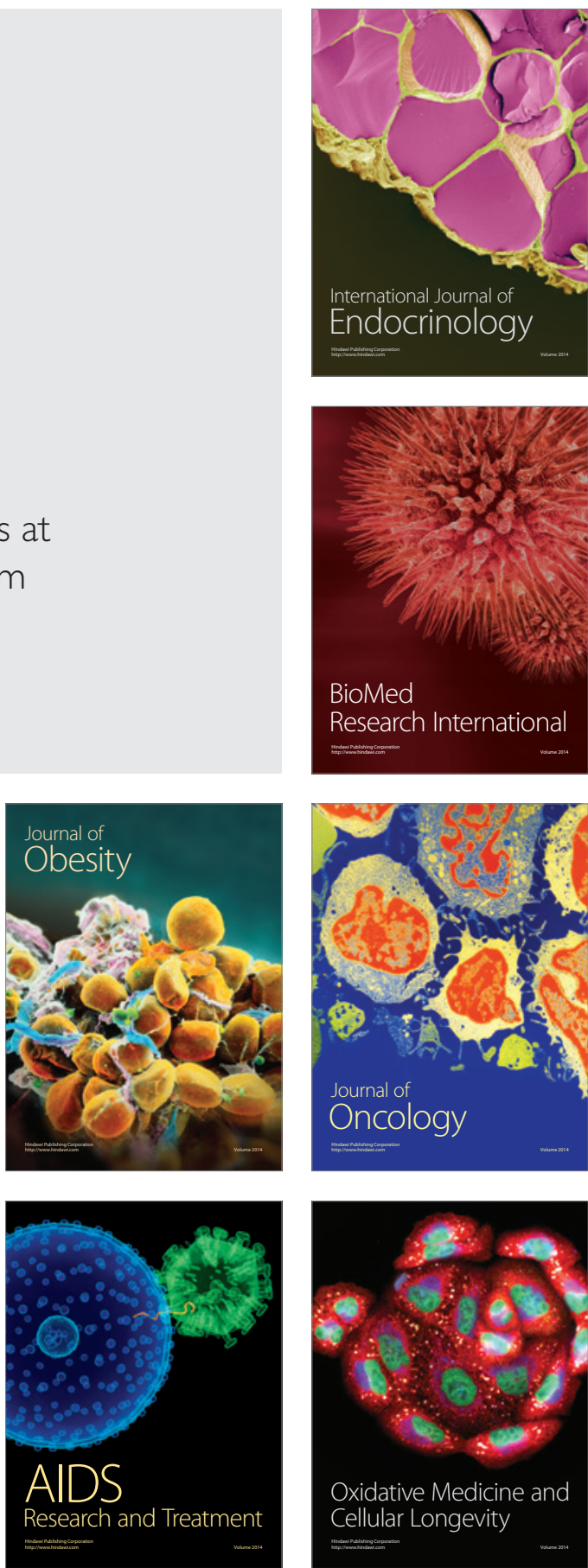